\title{
Hemodynamic and Hormonal Effects of Tolvaptan for Heart Failure
}

\author{
Shunsuke Kiuchi and Takanori Ikeda
}

\begin{abstract}
:
Tolvaptan (TLV) is a diuretic agent administrated for heart failure (HF) only in Japan. Many clinical findings have been obtained from the accumulation of clinical experience, and the administration of TLV reportedly avoids causing a reduction in the renal function. In addition, TLV has been reported to exert effects other than diuresis. The early start of TLV after hospitalization shortens the length of the hospital stay, and continuous TLV after discharge extends the period until re-hospitalization of HF patients. TLV is thought to function via vasopressin V2 receptor antagonism. However, no significant differences in the long-term prognosis were noted between the group using TLV and not using TLV in the Endovascular Valve Edge-to-Edge Repair Study (EVEREST) trial, and effects other than diuresis are not useful for all HF patients. Therefore, it is necessary to identify patients who may experience effects other than diuresis with TLV administration. The accumulation of more patients and findings from further large-scale clinical trials will be necessary in order to clarify these points.
\end{abstract}

Key words: tolvaptan, vasopressin, V2 receptor

(Intern Med 58: 471-475, 2019)

(DOI: 10.2169/internalmedicine.1697-18)

\section{Introduction}

In Japan, tolvaptan (TLV) was approved for heart failure (HF) patients suffering from fluid retention despite receiving standard treatment with conventional diuretics in December 2010 (1). However, while TLV is used to treat such HF patients in Japan, this agent has only been used to treat hyponatremia in other countries. It is no exaggeration to say that TLV, which operates via a novel diuretics mechanism that contrasts with water diuretics, has become an indispensable agent in the clinical setting based on the accumulation of seven years of clinical research. However, some clinical points remain unclear.

In this review, we focused on the mechanisms by which TLV exerts its activity and the results of clinical trials.

\section{The Diuretic Mechanism of Tolvaptan}

Diuretics (especially loop diuretics) have a central role in the treatment of HF, and the Japanese Cardiac Registry of
Heart Failure in Cardiology (JCARE-CARD) trial in 2003 reported that loop diuretics were used in $87.0 \%$ of cases (2). The frequency of use of diuretics has declined somewhat over the years since, but the CHART-2 study in 2015 reported that loop diuretics were still used in $55.5 \%$ of cases (3). However, despite their utility, increasing the dose of loop diuretics is known to increase the mortality rate of $\mathrm{HF}$ (4). One reason for this is a worsening renal function (WRF) caused by loop diuretics (5).

TLV reduces the WRF not only during hospitalization but also in the medium term after discharge $(6,7)$. This is because TLV mainly removes water from the third space, thereby preserving the renal hemodynamics and renal function (8). Arginine vasopressin (AVP) binds to the V2 receptor of the basolateral membrane of the collecting duct and phosphorylate of aquaporin (AQP) 2, which is a water channel, through cyclic AMP. AQP2 present on the membrane vesicle is then moved to the luminal membrane, thereby enhancing the water permeability (Figure). Free water flows into the cell and is reabsorbed via the basolateral membrane through AQP3 and AQP4 (9). Activation of the V2 receptor 


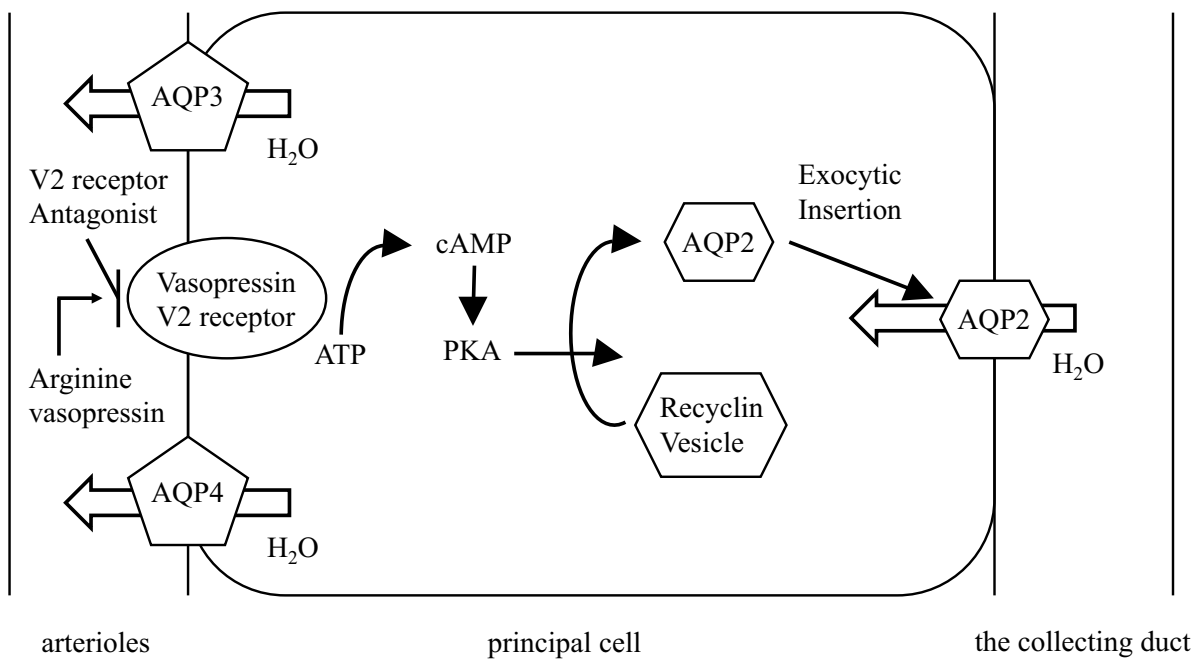

Figure. Diuretic Mechanisms of Tolvaptan. AQP: aquaporin, ATP: adenosine triphosphate, cAMP: cyclic adenosine monophosphate, PKA: protein kinase A

also reabsorbs $\mathrm{Na}^{+}$through the $\mathrm{Na}^{+} / \mathrm{K}^{+} / 2 \mathrm{Cl}^{-}$cotransporter in the ascending limb of the loop of Henle, the $\mathrm{Na}^{+} / \mathrm{Cl}^{-}$cotransporter in the distal tubule and the epithelial $\mathrm{Na}^{+}$channel of the collecting duct principal cells (10). TLV selectively antagonizes the V2 receptor, promoting diuresis (mainly of free water) and thereby improving hyponatremia.

\section{Vasopressin and Chronic HF}

AVP, a peptide neuroendocrine hormone secreted from the posterior pituitary gland, has three receptors: V1a, V1b and V2. V1a and V2 receptors are involved in hemodynamics (11). V1a receptor is associated with vasoconstriction and cardiac hypertrophy, and the action of V2 receptor is as described above. Therefore, the enhancement of AVP increases afterload via the stimulation of V1a receptor and preload via the stimulation of $\mathrm{V} 2$ receptor (12). In HF, however, AVP secretion is increased by non-osmotic pathways enhanced by a reduction in cardiac output (cardiac index) and/or hyperactivated renin angiotensin aldosterone system (13). It has been reported that the AVP levels in patients with HF are higher than in healthy persons (14) and increase further as the New York Heart Association classification rises (15). Furthermore, the AVP level is increased even in asymptomatic patients with cardiac systolic dysfunction (16). It has also been reported that AVP is involved in cardiac remodeling after myocardial infarction (17). However, although the long-term use of TLV improved the volume overload, the long-term use of TLV was not found to be particularly beneficial (18). Therefore, these findings of TLV are not attributed to the hemodynamics, but they are due to the effects of neurohormonal factors induced by vasopressin. The effectiveness of the long-term use of TLV in all $\mathrm{HF}$ patients was denied by the large-scale EVEREST trial and a meta-analysis $(19,20)$. Similarly, conivaptan, a V1a and V2 receptor antagonist that is approved only in the USA, shows no long-term benefits (21). However, in pa- tients with HF who maintain urine AQP2, the long-term use of TLV decreases the rates of death and rehospitalization (22). A meta-analysis reported that the subgroup of patients with hyponatremia might have a better mortality outcome with TLV than without its administration (23). We also previously reported that the long-term use of TLV prolonged the period until re-hospitalization (24). Therefore, in some patients, the long-term use of TLV may affect the outcomes of HF. However, predicting which patients will enjoy such benefits is difficult at present, and further clinical studies are necessary.

\section{Effectiveness of TLV for HF According to Clinical Trials}

After Gheorghiade first reported the effectiveness of TLV for chronic HF in 2003 (25), the large-scale EVEREST trial was conducted in 2007. In short-term trials of EVEREST, TLV increased diuresis and improved HF signs and symptoms in many patients (26). However, it has been reported that the use of TLV in the acute phase of HF significantly improved dyspnea and edema but had no effect on rales or pulmonary congestion (27). The backgrounds of subjects differed among these previous studies, though, so the QUEST trial on loop diuretics-resistant HF subjects was conducted in Japan (1). The administration of TLV for seven days increased the urine volume and improved HF symptoms in loop diuretics-resistant HF subjects. Based on these findings, TLV was approved in Japan for HF patients suffering from fluid retention despite receiving the standard treatment with conventional diuretics. Since the effectiveness of TLV depends on individual patients, it is important to consider ways to determine which HF patients will benefit the most from TLV. For example, the collecting duct function must be preserved in these patients, as TLV exerts its effect at the collecting duct. However, stress tests, such as the Fishberg concentration test, are not suitable for HF patients 
Table. Characteristics of Studies Regarding the Effectiveness and Safety for Early Use of Tolvaptan.

\begin{tabular}{|c|c|c|c|c|c|c|c|}
\hline Reference & Subjects & Country & $\begin{array}{l}\text { No, of patients } \\
\text { (\% of Male) }\end{array}$ & $\begin{array}{l}\text { Age (Years) } \\
\text { mean (S.D.) }\end{array}$ & $\begin{array}{l}\text { LVEF (\%) } \\
\text { mean (S.D.) }\end{array}$ & $\begin{array}{l}\text { Timing of initiation } \\
\text { of TLV from } \\
\text { hospitalization or } \\
\text { operation }\end{array}$ & Main outcomes \\
\hline 38 & $\begin{array}{l}\text { Underwent cardiac } \\
\text { surgery with } \\
\text { cardiopulmonary } \\
\text { bypass }\end{array}$ & Japan & $\begin{array}{l}\text { T: } 147 \text { (61.9) } \\
\text { C: } 133 \text { (55.6) }\end{array}$ & $\begin{array}{l}\text { T: } 70.8(11.4) \\
\text { C: } 69.5(12.2)\end{array}$ & $\begin{array}{l}\text { T: } 62.9(10.5) \\
\text { C: } 62.5(10.1)\end{array}$ & Within 24 hours & $\begin{array}{l}\text { body weight, } \\
\text { renal function }\end{array}$ \\
\hline 35 & ADHF & Japan & $\begin{array}{l}\text { T: } 31(48.4) \\
\text { C: } 25(56.0)\end{array}$ & $\begin{array}{l}\text { T: } 85.5 \text { (4.5) } \\
\text { C:86.7 (5.3) }\end{array}$ & $\begin{array}{l}\text { T: } 44.6(16.9) \\
\text { C: } 44.2(13.0)\end{array}$ & Within 24 hours & $\begin{array}{l}\text { body weight, } \\
\text { renal function, } \\
\text { hospital stay }\end{array}$ \\
\hline 36 & ADHF & Japan & $\begin{array}{c}\text { E: } 67(44.7) \\
\text { NE: } 35(77.1)\end{array}$ & $\begin{array}{c}\text { E: } 85.0(5.6) \\
\text { NE: } 61.3(9.4)\end{array}$ & $\begin{array}{c}\text { E: } 57.1(15.3) \\
\text { NE: } 44.3(20.9)\end{array}$ & NA & $\begin{array}{l}\text { renal function, } \\
\text { hospital stay, } \\
\text { mortality rate }\end{array}$ \\
\hline 34 & ADHF & Japan & $247(58.2)$ & $74.0(11.9)$ & 47.7 (18.8) & NA & hospital stay \\
\hline 37 & ADHF & Japan & $\begin{array}{c}\text { VE: } 45 \text { (42.2) } \\
\text { NVE: } 45(68.2)\end{array}$ & $\begin{array}{l}\text { VE: } 89 \\
\text { NVE: } 74\end{array}$ & $\begin{array}{c}\text { VE: } 49 \\
\text { NVE: } 44\end{array}$ & Within 24 hours & $\begin{array}{l}\text { renal function, } \\
\text { hospital stay, } \\
\text { in-hospital death }\end{array}$ \\
\hline 33 & $\begin{array}{c}\text { AHF and renal } \\
\text { dysfunction or } \\
\text { hyponatremia; or } \\
\text { diuretic resistance }\end{array}$ & $\begin{array}{l}\text { united } \\
\text { states }\end{array}$ & $\begin{array}{l}\mathrm{T}: 122(75.4) \\
\mathrm{C}: 128(72.7)\end{array}$ & $\begin{array}{l}\text { T: } 70(11) \\
\text { C: } 67 \text { (13) }\end{array}$ & $\begin{array}{l}\text { T: } 35 \text { (16) } \\
\text { C: } 33 \text { (17) }\end{array}$ & Within 36 hours & $\begin{array}{l}\text { dyspnea, body } \\
\text { weight, renal } \\
\text { function, death or } \\
\text { re-hospitalization } \\
\text { within } 30 \text { days }\end{array}$ \\
\hline 40 & $\mathrm{ADHF}$ & Japan & $\begin{array}{l}\text { T: } 26(38.5) \\
\text { C: } 26(46.2)\end{array}$ & $\begin{array}{l}\mathrm{T}: 80.5(12.2) \\
\mathrm{C}: 86.2(5.0)\end{array}$ & $\begin{array}{l}\text { T: } 47.5(16.8) \\
\text { C: } 56.7(11.5)\end{array}$ & Within 24 hours & $\begin{array}{l}\text { renal function, } \\
\text { death or re- } \\
\text { hospitalization } \\
\text { within } 90 \text { days }\end{array}$ \\
\hline 32 & $\mathrm{ADHF}$ & Japan & $\begin{array}{l}\text { R: } 77 \text { (61.0) } \\
\text { NR: } 12 \text { (48) }\end{array}$ & $\begin{array}{c}\text { R: } 76.7 \text { (13.6) } \\
\text { NR: } 77.3 \text { (12.5) }\end{array}$ & $\begin{array}{c}\text { R: } 53.8(18.0) \\
\text { NR: } 49.2(19.3)\end{array}$ & NA & $\begin{array}{l}\text { tolvaptan } \\
\text { response, cardiac } \\
\text { rehabilitation, } \\
\text { hospital stay, } \\
\text { in-hospital death }\end{array}$ \\
\hline 39 & $\begin{array}{c}\text { Underwent cardiac } \\
\text { surgery with heart } \\
\text { valve surgery }\end{array}$ & Japan & $\begin{array}{l}\text { T: } 39(56.4) \\
\text { C: } 42(54.8)\end{array}$ & $\begin{array}{l}\text { T: } 68 \text { (12) } \\
\text { C: } 66(14)\end{array}$ & $\begin{array}{l}\text { T: } 59.4(15.9) \\
\text { C: } 51.6(19.0)\end{array}$ & NA & $\begin{array}{l}\text { body weight, } \\
\text { serum sodium }\end{array}$ \\
\hline 31 & AHF & Japan & $\begin{array}{c}\text { T: } 52(76.9) \\
\text { C: } 131(58.0)\end{array}$ & $\begin{array}{l}\text { T: } 75 \\
\text { C: } 77\end{array}$ & $\begin{array}{l}\text { T: } 40 \\
\text { C: } 32\end{array}$ & Within 12 hours & $\begin{array}{l}\text { Renal function, } \\
\text { death within } 6 \\
\text { months }\end{array}$ \\
\hline
\end{tabular}

LVEF: Left Ventricular Ejection Fraction, S.D.: standard deviation, TLV: Tolvaptan, T: Tolvaptan group, C: Conventional group, E: Elderly group, NE: Elderly group, VE: Very elderly group, NVE: Non-very elderly group, AHF: acute heart failure, R: Response group, NR: Non-response group

in the acute phase. If the collecting duct function is maintained, AVP levels elevated by HF promote AQP2 expression, and the urinary AQP2 excretion also increases. Urinary AQP2 levels are reported to predict the effectiveness of TLV (22). However, measuring urinary AQP2 is not generally performed in the routine clinical setting. Urine osmolality has also proven useful for evaluating the efficacy of $\operatorname{TLV}(28,29)$, as has the ratio of AVP and the plasma aldosterone concentration (30).

\section{Effectiveness of TLV for Treating HF in the Acute Phase}

The renal function tends to decrease in the acute phase of HF treatment, although it is necessary to start TLV during hospitalization. In such cases, the renal function in these patients may be preserved by TLV, as mentioned above. Besides, the timing of the start of TLV after hospitalization is drawing attention, now. We summarized the outcomes of the early use of TLV for acute HF in Table. Shirakabe et al. reported that the early use of TLV ameliorated the renal function deterioration and improved the mid-term prognosis of HF (31). In addition, the early use of TLV for HF reduced the rate of in-hospital death $(32,33)$ and shortened the hospital stay (34). These effects were similarly reported in elderly patients (35-37) and after cardiac surgery $(38,39)$. The use of TLV within two to four days after hospitalization was classified as "early" in these retrospective studies.

There have been many prospective studies describing the outcomes of starting TLV within 24 hours after hospitalization (40). However, another point must be borne in mind: TLV was only approved for use in HF patients suffering from fluid retention despite receiving the standard treatment with conventional diuretics (1). Therefore, we must carefully consider patient background characteristics, although the early use of TLV after hospitalization is indeed useful. It has been reported that additional treatment of TLV is useful for HF patients in whom loop diuretics were originally adminis- 
tered but later developed resistance (41). The early use of TLV for acute exacerbation of chronic HF may also be effective. In addition to loop diuretics, the relationship between human atrial natriuretic peptide or thiazide and TLV has been investigated $(42,43)$. In a recent study, sodiumglucose cotransporter (SGLT) 2 inhibitor, which is a new therapeutic medication for diabetes mellitus, also attracted attention as a treatment for HF with diuretics action (44), and clinical trials are being conducted. However, which combination of TLV and other diuretics, including SGLT2 inhibitor, is the most effective remains unclear, so further clinical studies are necessary.

\section{Safety of TLV}

The patient's serum sodium concentration and ability to feel thirsty (or whether or not patients are able to drink) should be carefully monitored (1). It is recommended that the serum sodium concentration be evaluated before TLV administration, at 4 to 6 hours after TLV administration, at 8 to 12 hours after TLV administration and the next day. Clinical data accumulated over the seven years since TLV entered the market [post-marketing surveillance (Samsca Post-Marketing Surveillance In Heart faiLurE: SMILE study)] highlighted important clinical points concerning when to start TLV and the serum sodium concentration. It was reported in the SMILE study that the risk of hypernatremia increases when the serum sodium concentration exceeds $142 \mathrm{mEq} / \mathrm{L}$ and the serum potassium concentration is less than $3.8 \mathrm{mEq} / \mathrm{L}$ before the administration of TLV (45). Therefore, TLV should be initiated at a low dose in patients with a high risk of hypernatremia. In addition, it has been reported that the incidence of hypernatremia is increased in patients $\geq 80$ years of age compared with those $<80$ years of age (46). However, the long-term use of TLV (for more than 15 days) reportedly does not increase the risk of hypernatremia (47). The safety and effectiveness of using TLV for children has been reported as well (48), so hypernatremia may be able to be avoided by the long-term use of TLV if we identify groups at high risk of hypernatremia and initiate TLV at relatively low doses, such as $3.75 \mathrm{mg} /$ day. Although a meta-analysis reported in 2017 that TLV was not associated with an increased risk of adverse events (49), one report has claimed that the long-term use of TLV increased the risk of adverse events by $14 \%$ (20). The risk of adverse events should be evaluated when considering the continued use of TLV (especially in the long term).

\section{Conclusion}

We outlined the effectiveness and safety of TLV. TLV is useful for many $\mathrm{HF}$ patients (including long-term use). However, many points remain unclear, such as how to identify which patients will most benefit from TLV. The accumulation of more evidence supporting the appropriate use of TLV is needed.
The authors state that they have no Conflict of Interest (COI).

\section{References}

1. Matsuzaki M, Hori M, Izumi T, Fukunami M. Tolvaptan investigators. Efficacy and safety of tolvaptan in heart failure patients with volume overload despite the standard treatment with conventional diuretics: a phase III, randomized, double-blind, placebo-controlled study (QUEST study). Cardiovasc Drugs Ther 25(suppl 1): S33-S 45, 2011.

2. Tsuchihashi-Makaya M, Hamaguchi S, Kinugawa S, et al. Characteristics and outcomes of hospitalized patients with heart failure and reduced vs preserved ejection fraction. Report from the Japanese Cardiac Registry of Heart Failure in Cardiology (JCARECARD). Circ J 73: 1893-1900, 2009.

3. Ushigome R, Sakata Y, Nochioka K, et al. Temporal trends in clinical characteristics, management and prognosis of patients with symptomatic heart failure in Japan - report from the CHART Studies. Circ J 79: 2396-2407, 2015.

4. Hasselblad V, Gattis Stough W, Shah MR, et al. Relation between dose of loop diuretics and outcomes in a heart failure population: results of the ESCAPE trial. Eur J Heart Fail 9: 1064-1069, 2007.

5. Maeder MT, Rickli H, Pfisterer ME, et al. Incidence, clinical predictors, and prognostic impact of worsening renal function in elderly patients with chronic heart failure on intensive medical therapy. Am Heart J 163: 407-414, 2012.

6. Matsue Y, Suzuki M, Seya M, et al. Tolvaptan reduces the risk of worsening renal function in patients with acute decompensated heart failure in high-risk population. J Cardiol 61: 169-174, 2013.

7. Nakano Y, Mizuno T, Niwa T, et al. Impact of continuous administration of tolvaptan on preventing medium-term worsening renal function and long-term adverse events in heart failure patients with chronic kidney disease. Int Heart J 59: 105-111, 2018.

8. Costello-Boerrigter LC, Smith WB, Boerrigter G, et al. Vasopressin-2-receptor antagonism augments water excretion without changes in renal hemodynamics or sodium and potassium excretion in human heart failure. Am J Physiol Renal Physiol 290: F273-F278, 2006.

9. Yamashita Y, Hirai K, Katayama Y, Fushimi K, Sasaki S, Marumo F. Mutations in sixth transmembrane domain of AQP2 inhibit its translocation induced by vasopression. Am J Physiol Renal Physiol 278: F395-F405, 2000.

10. Stockand JD. Vasopressin regulation of renal sodium excretion. Kidney Int 78: 849-856, 2010.

11. Vinod P, Krishnappa V, Chauvin AM, Khare A, Raina R. Cardiorenal syndrome: role of arginine vasopressin and vaptans in heart failure. Cardiol Res 8: 87-95, 2017.

12. Niizuma S, Iwanaga Y. Revisiting vasopressin and heart failure. Expert Rev Cardiovasc Ther 11: 1451-1454, 2013.

13. Imamura $T$, Kinugawa $K$, Hatano $M$, et al. Low cardiac output stimulates vasopressin release in patients with stage $\mathrm{d}$ heart failure. Circ J 78: 2259-2267, 2014.

14. Goldsmith SR, Francis GS, Cowley AW Jr, Levine TB, Cohn JN. Increased plasma arginine vasopressin levels in patients with congestive heart failure. J Am Coll Cardiol 1: 1385-1390, 1983.

15. Nakamura T, Funayama H, Yoshimura A, et al. Possible vascular role of increased plasma arginine vasopressin in congestive heart failure. Int J Cardiol 106: 191-195, 2006.

16. Francis GS, Benedict C, Johnstone DE, et al. Comparison of neuroendocrine activation in patients with left ventricular dysfunction with and without congestive heart failure. A substudy of the Studies of Left Ventricular Dysfunction (SOLVD). Circulation 82: 1724-1729, 1990.

17. Kelly D, Squire IB, Khan SQ, et al. C-terminal provasopressin (copeptin) is associated with left ventricular dysfunction, remodeling, and clinical heart failure in survivors of myocardial infarction. J Card Fail 14: 739-745, 2008. 
18. Xiong B, Huang Y, Tan J, et al. The short-term and long-term effects of tolvaptan in patients with heart failure: a meta-analysis of randomized controlled trials. Heart Fail Rev 20: 633-642, 2015.

19. Konstam MA, Gheorghiade M, Burnett JC Jr, et al.; Efficacy of Vasopressin Antagonism in Heart Failure Outcome Study With Tolvaptan (EVEREST) Investigators. Effects of oral tolvaptan in patients hospitalized for worsening heart failure. The EVEREST outcome trial. JAMA 297: 1319-1331, 2007.

20. Nistor I, Bararu I, Apavaloaie MC, et al. Vasopressin receptor antagonists for the treatment of heart failure: a systematic review and meta-analysis of randomized controlled trials. Int Urol Nephrol 47: 335-344, 2015.

21. Gassanov N, Semmo N, Semmo M, Nia AM, Fuhr U, Er F. Arginine vasopressin (AVP) and treatment with arginine vasopressin receptor antagonists (vaptans) in congestive heart failure, liver cirrhosis and syndrome of inappropriate antidiuretic hormone secretion (SIADH). Eur J Clin Pharmacol 67: 333-346, 2011.

22. Imamura $T$, Kinugawa $K$, Fujino $T$, et al. Increased urine aquaporin-2 relative to plasma arginine vasopressin is a novel marker of response to tolvaptan in patients with decompensated heart failure. Circ J 78: 2240-2249, 2014.

23. Alskaf E, Tridente A, Al-Mohammad A. Tolvaptan for heart failure, systematic review and meta-analysis of trials. J Cardiovasc Pharmacol 68: 196-203, 2016.

24. Kiuchi S, Fujii T, Hisatake S, et al. Experience with long-term administration of tolvaptan to patients with acute decompensated heart failure. Drug Discov Ther 11: 133-139, 2017.

25. Gheorghiade M, Niazi I, Ouyang J, et al. Vasopressin V2-receptor blockade with tolvaptan in patients with chronic heart failure: results from a double-blind, randomized trial. Circulation 107: 26902696, 2003.

26. Gheorghiade M, Konstam MA, Burnett JC Jr, et al. Short-term clinical effects of tolvaptan, an oral vasopressin antagonist, in patients hospitalized for heart failure: the EVEREST Clinical Status Trials. JAMA 297: 1332-1343, 2007.

27. Yang CJ, Yang J, Yang J, Fan ZX. Arginine vasopressin antagonist tolvaptan in the treatment of heart failure: a meta-analysis of randomized controlled trials. Int J Clin Exp Med 8: 22117-22128, 2015.

28. Imamura T, Kinugawa K, Shiga T, et al. Novel criteria of urine osmolality effectively predict response to tolvaptan in decompensated heart failure patients-association between non-responders and chronic kidney disease. Circ J 77: 397-404, 2013.

29. Imamura $T$, Kinugawa $K$, Minatsuki $S$, et al. Urine osmolality estimated using urine urea nitrogen, sodium and creatinine can effectively predict response to tolvaptan in decompensated heart failure patients. Circ J 77: 1208-1213, 2013.

30. Kadota M, Ise T, Yagi S, et al. Response prediction and influence of tolvaptan in chronic heart failure patients considering the interaction of the renin angiotensin aldosterone system and arginine vasopressin. Int Heart J 57: 461-465, 2016.

31. Shirakabe A, Hata N, Yamamoto M, et al. Immediate administration of tolvaptan prevents the exacerbation of acute kidney injury and improves the mid-term prognosis of patients with severely decompensated acute heart failure. Circ J 78: 911-921, 2014.

32. Matsukawa R, Kubota T, Okabe M, Yamamoto Y. Early use of V2 receptor antagonists is associated with a shorter hospital stay and reduction in in-hospital death in patients with decompensated heart failure. Heart Vessels 31: 1650-1658, 2016.

33. Konstam MA, Kiernan M, Chandler A, et al. Short-term effects of tolvaptan in patients with acute heart failure and volume overload. J Am Coll Cardiol 69: 1409-1419, 2017.
34. Kiuchi S, Hisatake S, Kabuki T, et al. The relationship between the time until commencement of tolvaptan and the length of hospital stay in heart failure patients. Heart Vessels 33: 367-373, 2018.

35. Kinoshita M, Okayama H, Kosaki T, et al. Favorable effects of early tolvaptan administration in very elderly patients after repeat hospitalization for acute decompensated heart failure. Heart Vessels 33: 163-169, 2018.

36. Matsukawa R, Kubota T, Okabe M, Yamamoto Y, Meno H. Efficacy and safety of the early use of V2 receptor antagonists in elder patients with decompensated heart failure. Heart Vessels 33: 145-154, 2018.

37. Niikura H, Iijima R, Anzai H, et al. Clinical utility of early use of tolvaptan in very elderly patients with acute decompensated heart failure. Anatol J Cardiol 18: 206-212, 2017.

38. Kishimoto Y, Nakamura Y, Harada S, et al. Can tolvaptan protect renal function in the early postoperative period of cardiac surgery? Results of a single center randomized controlled study. Circ J 82: 999-1007, 2018.

39. Nishi H, Toda K, Miyagawa S, et al. Effects of tolvaptan in the early postoperative stage after heart valve surgery results of the STAR (Study of Tolvaptan for fluid retention AfteR valve surgery) trial. Surg Today 45: 1542-1551, 2015.

40. Kimura K, Momose T, Hasegawa T, et al. Early administration of tolvaptan preserves renal function in elderly patients with acute decompensated heart failure. J Cardiol 67: 399-405, 2016.

41. Suzuki S, Yoshihisa A, Yamaki T, et al. Acute heart failure volume control multicenter randomized (AVCMA) trial: comparison of tolvaptan and carperitide. J Clin Pharmacol 53: 1277-1285, 2013.

42. Inomata T, Ikeda $Y$, Kida K, et al. Effects of additive tolvaptan vs. increased furosemide on heart failure with diuretic resistance and renal impairment -Results from the K-STAR study. Circ J 82: 159167, 2017.

43. Imamura $T$, Kinugawa $\mathrm{K}$, Kato $\mathrm{N}$, et al. Successful conversion from thiazide to tolvaptan in a patient with stage $d$ heart failure and chronic kidney disease before heart transplantation. Int Heart $\mathrm{J}$ 54: 48-50, 2013.

44. Kiuchi S, Hisatake S, Kabuki T, et al. Long-term use of ipragliflozin improved cardiac sympathetic nerve activity in a patient with heart failure: a case report. Drug Discov Ther 12: 51-54, 2018.

45. Kinugawa K, Sato N, Inomata $\mathrm{T}$, Shimakawa $\mathrm{T}$, Iwatake $\mathrm{N}$, Mizuguchi K. Efficacy and safety of tolvaptan in heart failure patients with volume overload. Circ J 78: 844-852, 2014.

46. Kinugawa K, Inomata T, Sato N, et al. Effectiveness and adverse events of tolvaptan in octogenarians with heart failure. Interim analyses of Samsca Post-Marketing Surveillance In Heart faiLurE (SMILE study). Int Heart J 56: 137-143, 2015.

47. Kinugawa K, Inomata $\mathrm{T}$, Sato $\mathrm{N}$, et al. Who needs longer tolvaptan treatment? Int Heart J 58: 30-35, 2017.

48. Higashi K, Murakami T, Ishikawa $Y$, et al. Efficacy and safety of tolvaptan for pediatric patients with congestive heart failure. Multicenter survey in the working group of the Japanese Society of PEdiatric Circulation and Hemodynamics (J-SPECH). Int J Cardiol 205: 37-42, 2016.

49. Wu MY, Chen TT, Chen YC, et al. Effects and safety of oral tolvaptan in patients with congestive heart failure: a systematic review and network meta-analysis. PLoS One 12: e0184380, 2017.

The Internal Medicine is an Open Access journal distributed under the Creative Commons Attribution-NonCommercial-NoDerivatives 4.0 International License. To view the details of this license, please visit (https://creativecommons.org/licenses/ by-nc-nd/4.0/).

(C) 2019 The Japanese Society of Internal Medicine Intern Med 58: 471-475, 2019 